\title{
Factors Affecting Health Care Provider Knowledge and Acceptance of Biosimilar Medicines: A Systematic Review
}

\author{
Emily Leonard, PharmD Candidate; Michael Wascovich, PharmD, MBA; \\ Sonia Oskouei, PharmD; Paula Gurz, MBA; and Delesha Carpenter, PhD, MSPH
}

\begin{abstract}
BACKGROUND: Newly developed biosimilar agents confer significant costsaving advantages, yielding the potential to mitigate rising drug costs and expand patient access to care for important biologic therapies. Biosimilar market uptake greatly depends on health care provider willingness to promote, prescribe, and use biosimilars in clinical practice.
\end{abstract}

OBJECTIVE: To perform a systematic review evaluating current U.S. and European health care provider knowledge, perceptions, and prescribing behaviors of biosimilar medicines to assess the need for clinician-directed biosimilar education.

METHODS: An electronic literature search was conducted using journal databases, including PubMed, Embase, and Cochrane Library. Terms related to biosimilar agents, survey questionnaires, and education were used. Two independent reviewers evaluated 158 citations published from January 1 , 2014, to March 5, 2018 that were the result of this search. Studies in English were included if they surveyed U.S. or European physician and/or pharmacist knowledge, attitudes, and/or prescribing preferences of biosimilar drugs. Overall trends in prescribing behavior and perceptions were abstracted.

RESULTS: A total of 20 studies met inclusion criteria. Three studies originated from the United States and 17 were from Europe. Hospital specialists, gastroenterologists, and rheumatologists were the most frequently surveyed practitioners. The percentage of biosimilar prescribing varied widely between countries and within similar practice fields. If used, biosimilars were predominantly prescribed in biologic treatment-naive patients. An overall lack of biosimilar familiarity in U.S. and European health care settings accompanied concerns about biosimilar safety, efficacy, extrapolation, and interchangeability. Detailed descriptions of biosimilar education programs were lacking within the literature.

CONCLUSIONS: Findings from this review indicate that U.S. and European health care providers still approach biosimilar medicines with caution, citing limited biosimilar knowledge, low prescribing comfort, and safety and efficacy concerns as main deterrents for biosimilar use. To realize the full cost-saving potential of biosimilar medicines, clinician-directed biosimilar education will be imperative to address gaps in biosimilar knowledge, facilitate prescribing changes, and ultimately increase biosimilar use.

J Manag Care Spec Pharm. 2019;25(1):102-12

Copyright $\odot 2019$, Academy of Managed Care Pharmacy. All rights reserved.

\section{What is already known about this subject}

Patents of key biologic therapies have expired or will expire by 2020, which is driving pharmaceutical manufacturer interest in biosimilar drug development.

In Europe, cost-effective biosimilar medicines have been shown to increase patient access to care earlier in the therapy cycle, decreasing costs and improving health outcomes for patients.

Biosimilar use and market uptake are contingent, in part, on physician and pharmacist confidence and willingness to prescribe, promote, and use biosimilar medicines in clinical practice.

\section{What this study adds}

This review evaluated 20 U.S. and European health care provider surveys published from 2014 to 2017 for data related to providers' biosimilar prescribing habits, knowledge, safety and efficacy concerns, extrapolation and interchangeability viewpoints, and exposure to biosimilar educational activities.

Study results showed that health care providers in the United States and Europe lack biosimilar familiarity and understanding, contributing to safety and efficacy concerns and limited biosimilar prescribing.

To help promote biosimilar uptake, education directed at health care providers and key physician stakeholders will likely help to close the knowledge gap, improve confidence in biosimilar medicines, and increase biosimilar prescribing.

D rescription drug spending in the United States has received a great deal of attention as a pathway to potentially cut rising health care costs. After several years of slowed growth, 2016 saw a 5.8\% increase in pharmaceutical expenditures across all health care sectors, totaling \$448.2 billion. ${ }^{1}$ Biologic agents account for nearly $\$ 2.0$ billion in U.S. nonfederal hospital costs, with adalimumab, etanercept, and infliximab constituting 3 out of the top 5 most expensive drugs overall. ${ }^{1}$ These agents are tumor necrosis factor (TNF) alpha inhibitors and are important guideline-recommended therapies for the treatment of patients with inflammatory rheumatic disease or inflammatory bowel disease (IBD) refractory to conventional immunosuppressive treatments. ${ }^{2}$ The high costs of these medications have resulted in the development of biosimilar medications, which may confer significant 
cost-saving advantages over biologics, yielding the potential to mitigate rising drug costs and expand patient access to important biologic therapies.

The U.S. Food and Drug Administration (FDA) defines a biosimilar product as highly similar but not identical to an already licensed biologic product (also termed reference product or bio-originator) in terms of quality, safety, and efficacy. ${ }^{3}$ As of February 2018, 9 biosimilars have received FDA approval, yet only 3 have made it to the U.S. market. ${ }^{4}$ In comparison, Europe has 41 approved biosimilars and generates the most biosimilar revenue worldwide. ${ }^{5,6}$ Still, initial biosimilar uptake in both economies has been slow. ${ }^{6-8}$ Slowed biosimilar growth has been attributed to a time-consuming approval process marked by regulatory challenges, legal issues, payer policy disparities, and clinician concerns. ${ }^{7,9,10}$ Limited reports have highlighted physician and pharmacist reluctance to accept biosimilars as equal to the reference product but fail to describe what specific biosimilar factors contribute to clinician uncertainty. ${ }^{7,8,11,12}$ The evolving biosimilar pipeline currently includes over 800 biosimilar drug candidates in development. ${ }^{13}$ As more biosimilars seek market entry, understanding current clinician attitudes and awareness of biosimilars is important to assess the need for biosimilar education, promote utilization, and, ultimately, help drive down biologic therapy costs.

\section{Methods}

\section{Search Strategy}

The PRISMA guidelines were followed throughout this review. Relevant English-language articles indexed in PubMed, Embase, and Cochrane Library databases from January 1, 2014, to March 5, 2018, were searched on March 7, 2018. In addition, the reference lists of identified publications were hand-searched and screened for relevance. The search strategy used the following PubMed medical subject headings (MeSH) terms and text words: biosimilar, biosimilar agent, questionnaire, health survey, attitude, education, learning, and drug formulary. Search terms were modified for Embase and Cochrane Library according to the capabilities of each database.

\section{Review Process}

Search results were imported into Covidence Systemic Review Software (Covidence, Melbourne, Australia), where 2 independent reviewers (authors Leonard and Wascovich) screened titles and abstracts for relevance. Initial disagreements on which articles were eligible were resolved, with both reviewers reaching consensus on which articles to include for full-text review. Studies were eligible for full-text review if they were (a) a journal article, conference proceeding, poster abstract, or editorial letter and (b) surveyed U.S. or European physician and/ or pharmacist knowledge, attitudes, and/or prescribing preferences of biosimilar medicines. Europe is considered to have the most seasoned users of biosimilars, with use since 2006. ${ }^{14}$ In 2016, 9 out of 10 global biosimilar product sales were in Europe. ${ }^{14}$ Therefore, it was selected for analysis based on its extent of biosimilar experience, and the United States was selected to better understand the domestic market that U.S. clinicians practice in. Articles were excluded if they focused exclusively on budget cost analyses; only surveyed patients, nonprescribing nurses, or other nonprescribing health care providers; were general biosimilar overviews; or were published in a language other than English. The resulting full-text copies of all studies considered to be of potential relevance were retrieved and screened by 1 author (Leonard).

\section{Data Collection}

Data from included studies were extracted into MS Excel 2016 (Microsoft Corporation, Redmond, WA) by 1 of the 2 initial reviewers (author Leonard) and independently checked by a second reviewer from among the authors of this study for methodological quality and completeness. The following characteristics were retrieved: general information (first author, year of publication, country of publication); method (online survey vs. semistructured interview, sampling method used, provider type); sample size; response rate; study outcomes; and conclusions.

In addition, 4 topics for data extraction were identified a priori based on a collaborative discussion between study authors (Leonard, Wascovich, Oskouei, and Gurz). Relevant experiences of these colleagues to the current study include leading national biosimilar strategy on behalf of nearly 3,800 hospitals and health systems; researching health system stakeholders' evaluation and management of biosimilars; and supporting biosimilar contracting, pharmacy purchasing, and procurement. Topics included the following: (a) clinician biosimilar prescribing behaviors; (b) clinician biosimilar knowledge; (c) biosimilar clinical concerns; and (d) biosimilar education programs for providers. These topic areas were specifically identified as key areas of unknown knowledge through health system stakeholder interviews and surveys, professional conferences, and biosimilar manufacturer engagements as related to the study authors' professional roles.

Biosimilar prescribing behaviors were categorized as the percentage of clinicians currently prescribing biosimilar medicines or the percentage of clinicians willing to prescribe biosimilar medicines. Biosimilar knowledge included knowledge of the FDA or European Medicines Agency (EMA) definition of a biosimilar medicine or reported familiarity with the concept of biosimilar medicines. Clinical concerns included problems expressed relating to biosimilar safety, efficacy, extrapolation, or pharmacy-driven substitution. Biosimilar education was categorized as clinicians' means of biosimilar education or clinicians' biosimilar educational preferences. 


\section{FIGURE 1 Flow Diagram of Article Selection Process}

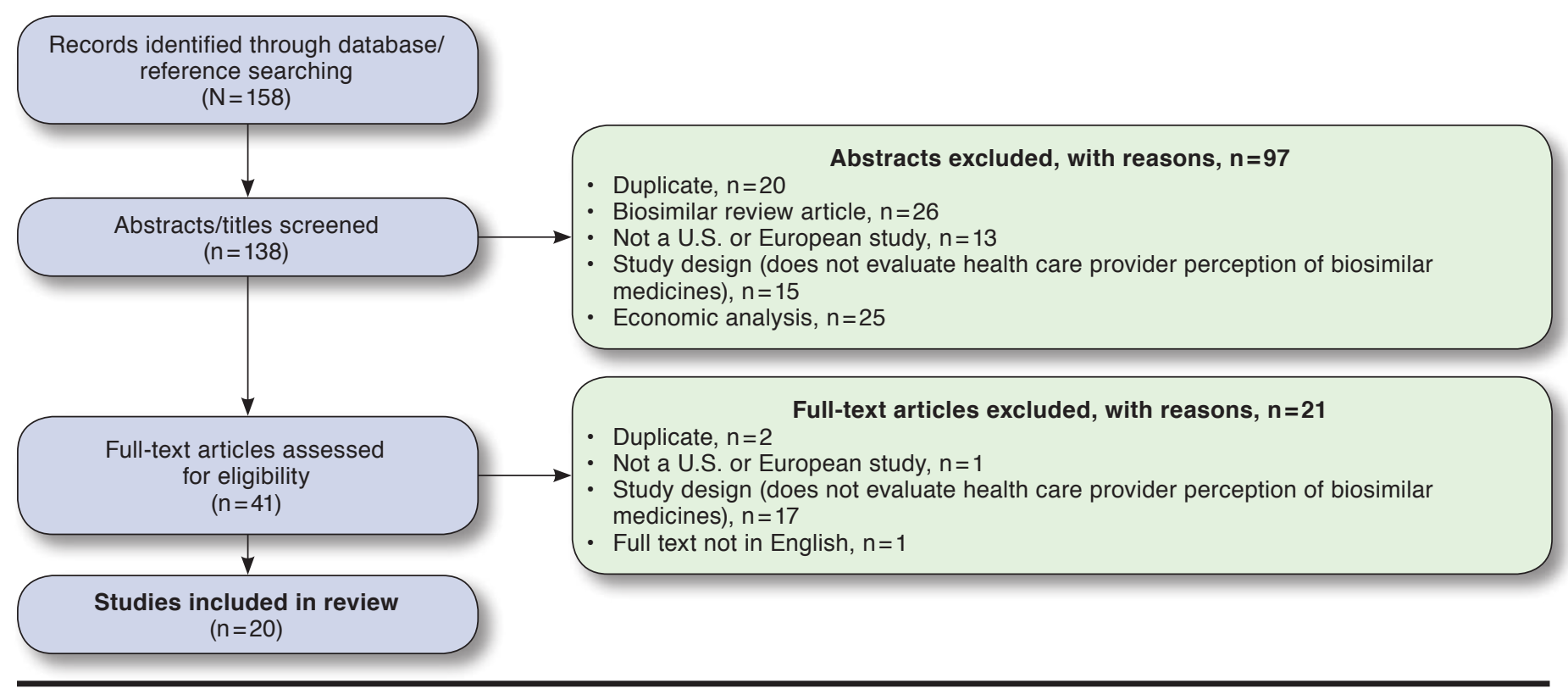

\section{Results}

The searches identified 158 records, which resulted in 138 nonduplicate items. Twenty surveys met the inclusion criteria and were included in this systematic review (Figure 1). The included studies originated from the United States, Belgium, France, Germany, Italy, Ireland, Malta, Hungary, and the United Kingdom (Table 1). ${ }^{15-29}$ Five surveys included multiple European states (Table 1). ${ }^{30-34}$

\section{Biosimilar Prescribing Behaviors}

Sixteen studies quantified clinicians' biosimilar prescribing habits. ${ }^{15,17,29-34,19,21-26,28}$ In Danese et al. (2014), 61\% of gastroenterologists felt little or no confidence in using biosimilars; 26\% felt confident enough; $8 \%$ felt very confident; and 5\% felt totally confident. When the survey was repeated 1 year after biosimilars became available in Europe, confidence had increased, as $19.5 \%$ of gastroenterologists felt little or no confidence in using biosimilars; $33.9 \%$ felt confident enough; $17.8 \%$ felt very confident; and $28.8 \%$ felt totally confident (2016). ${ }^{31}$

In Beck et al. (2016) and van Overbeeke et al. (2016), approximately $7 \%$ of rheumatologists had prescribed at least 1 biosimilar. ${ }^{19,21}$ In another 2016 French survey, 22\% of physicians reported writing $\geq 1$ biosimilar prescription per week; $30.5 \%$ wrote between 6 and 12 biosimilar prescriptions per year; and $47 \%$ wrote $<6$ biosimilar prescriptions per year. ${ }^{22}$ In Pasina et al. (2016), 51\% of clinicians prescribed biosimilars to biologic-naive patients only, while $25 \%$ also prescribed biosimilars to patients with previous biologic exposure. ${ }^{25}$ Greater than $50 \%$ biosimilar prescribing was reported in Hallersten et al. (2016) and Kellner et al. (2016). ${ }^{32,33}$ Kellner et al. identified a general correlation between length of biosimilar exposure and willingness to prescribe biosimilars, although specific details of this correlation were not described in the published abstract. ${ }^{33}$

In Narayanan et al. (2016), 60\% of rheumatologists reported a high likelihood to prescribe biosimilars, but they also reported that they would limit use to a small patient population first. ${ }^{34}$ Years of practice experience did not significantly affect prescribing preferences; however, a higher proportion (57\%) of rheumatologists with $>20$ years of practice experience identified the lack of biosimilar long-term data as a key impediment to prescribing. ${ }^{34}$ Limited biosimilar use in a small, select group of patients was also reported by 38\% of respondents in Barsell et al. (2017). ${ }^{15}$

Biosimilars were still largely considered second-line therapies mainly prescribed for biologic-naive patients. Eighty-eight percent of gastroenterologists in Sullivan et al. (2017) and 95\% of rheumatologists in Waller et al. (2017) preferred to prescribe a bio-originator to a biosimilar as first-line therapy for IBD or rheumatic diseases, respectively. ${ }^{23,24}$ Correspondingly, biosimilars only made up 13\% and 10\% of biologic therapies prescribed by physicians in Sullivan et al. and Waller et al. ${ }^{23,24}$ In Gibofsky et al. (2017), 66\% of rheumatologists were only likely to start biosimilar therapy in biologic treatment-naive individuals. ${ }^{17}$ Specialists also primarily prescribed biosimilars in biologic treatment-naive patients in O'Callaghan et al. (2017), Chapman et al. (2017), and Baji et al. (2016). ${ }^{26-28}$ 


\section{TABLE 1 Summary of Key Information from Articles that Met Inclusion Criteria}

Author, Country,

Journal

Adé et al 20

France

Ann Pharm Fra

2017

(

\section{Baji et al. ${ }^{28}$}

Hungary

Scand J

Gastroenterol

2016

\section{Barsell et al.15}

United States

J Drugs Dermatol

2017

2017

France

BioDrugs

2016
Sample size: $\mathrm{n}=116$

Response rate: N/A

Sampling: N/A

Methods: online survey

Sample: rheumatologists

Date: 06/08/15-08/02/15
Cassar et al. ${ }^{27}$

Malta

Ann Rheum Dis

2016
Sample size: $\mathrm{n}=132$

Response rate: $14 \%$

Sampling: N/A

Methods: online survey

Sample: physicians

Date: N/A

Chapman et al. ${ }^{29}$

United Kingdom

BMJ Open

2017

\section{(}

\section{Sample size: $\mathrm{n}=234$}

Response rate: N/A

Sampling: N/A

Methods: online survey

Sample: specialty physicians,

pharmacists, nurses

Date: 08/01/16-01/08/16

\begin{tabular}{|c|c|}
\hline Objective & Outcomes \\
\hline $\begin{array}{l}\text { To assess } \\
\text { pharmacists' } \\
\text { knowledge and } \\
\text { views of biosimilars } \\
\text { in France and } \\
\text { Quebec }\end{array}$ & $\begin{array}{l}\text { 1. } 26 \% \text { of French respondents did not receive specific } \\
\text { biosimilar training } \\
\text { 2. The majority lacked knowledge of biosimilar } \\
\text { development processes } \\
\text { 3. Only } 36 \% \text { of pharmacists were comfortable with } \\
\text { biosimilar extrapolation to all indications approved } \\
\text { for the originator product }\end{array}$ \\
\hline To assess & $\begin{array}{l}\text { 1. } 65 \% \text { reported safety and/or efficacy concerns about } \\
\text { biosimilar use in CD patients }\end{array}$ \\
\hline
\end{tabular}

2. Physicians preferred to select the reference product over the biosimilar $60 \%$ of the time in biologic-naive patients and $74 \%$ of the time in patients already treated with the bio-originator

1. $62 \%$ described having a basic understanding of biosimilars but could not define them

2. $84 \%$ prescribed biologics in their practice; $25 \%$ will definitely or are highly likely to prescribe biosimilars; $38 \%$ will try using biosimilars in a small group of patients first

3. Physicians familiarized themselves with biosimilars via 3 main methods: self-study (35\%), scientific publications (25\%), and conferences/seminars (17\%)

4. Major hesitancies include safety (66\%), efficacy (71\%) immunogenicity (63\%), and potential for patients to be switched from a biologic to a biosimilar without clinician knowledge (68\%)

\begin{tabular}{l|l} 
To assess French & 1. Only $7 \%$ of rheumatologists had already prescribed
\end{tabular} rheumatologist

knowledge, experience, and opinions of biosimilar medicines and identify factors to promote biosimilar prescribing

To assess Maltese clinicians' perceptions of biosimilars biosimilars

2. $67 \%$ of respondents did not feel comfortable with biosimilar extrapolation to all indications of the reference medicinal product

3. $89 \%$ would initiate biosimilar therapy in biologic treatment-naive patients

4. Only $25 \%$ would switch from originator to biosimilar in patients responding well to bio-originator therapy

5. $98.3 \%$ of participants had $\geq 1$ remaining question about biosimilar medicines

1. $59 \%$ of respondents could not define biosimilars or had never heard of them

2. Only $36 \%$ believed reference products and biosimilars safely yield the same results

3. Only $27 \%$ of physicians agreed that patients can be safely switched between products during treatment; $46 \%$ believe it is critical that physicians have the sole authority over switching

To compare health care professionals' knowledge, attitudes, and utilization of infliximab and insulin glargine biosimilars

\section{1. $93 \%$ of gastroenterologists and $90 \%$ of} rheumatologists reported no or minor safety/efficacy concerns when initiating biosimilar therapy for biologic-naive patients

2. Rheumatologists had major concerns about safety (53\%) and efficacy (55\%) when switching patients from bio-originator to biosimilar

3. Gastroenterologists prescribed biosimilar infliximab (62\%) more than rheumatologists (39\%) in 2016

4. Most respondents weighted NICE guidance and pharmacovigilance studies as factors that were likely to increase their use of biosimilars
Main Limitations

Greater than 50\% of respondents were interns in training

Sample selection bias; since May 2014 in Hungary, newly started infliximab therapy must be undertaken with a biosimilar antibody

Small sample size potential for nonresponder bias

Biosimilar infliximab was the only biosimilar medicine available in rheumatology at the time survey was conducted; study reflects knowledge, experience,

and opinions of $4.5 \%$ of French rheumatologists (116 of 2,598 rheumatologists in France in 2014)

Survey date not reported in abstract

Estimated low response rate, around $10 \%$ 


\section{TABLE 1 Summary of Key Information from Articles that Met Inclusion Criteria (continued)}

Author, Country,

Journal

Cohen et al. ${ }^{16}$

United States

Adv Ther

2016

Methods: survey
Sample: specialty physicians
Date: 11/20/15-01/04/16

\begin{tabular}{l|l|l} 
& \multirow{2}{*}{} & biosimilar drugs \\
& & \\
\hline Danese et al 30 & Sample size: $n=307$ & To evaluate
\end{tabular}

Danese et al.30

Europe

J Crohns Colitis

2014
Sample size: $\mathrm{n}=118$

Response rate: N/A

Sampling: N/A

Methods: online survey

Sample: gastroenterologists

Date: 06/01/15-11/30/15
To assess ECCO members' evolving views of biosimilar medicines after the introduction of biosimilar infliximab to European markets in 2015

\section{Sample size: $\mathrm{n}=19$}

Response rate: $30 \%$

Belgium

PharmacoEconomics

To identify biosimilar uptake 2014

Sampling: selective

Methods: semi-structured

interviews

Sample: physicians,

pharmacists, patients,

academia, industry

Date: 10/2012-02/2013

Gibofsky et al. ${ }^{17}$

United States

Arthritis Rheumatol

2017
Hallersten et al. 32 United Kingdom, France, Italy, Spain Germany, Poland, Sweden Regul Toxicol Pharmacol 2016
Sample size: $\mathrm{n}=307$

Response rate: N/A

Sampling: N/A

Methods: online survey

Sample: gastroenterologists

Date: 10/20/13-11/30/13 gastroenterologists' awareness of biosimilar mAbs and their readines to prescribe these therapies
Outcomes

1. Physician knowledge about biosimilar development process and totality of evidence was low

2. Only $12 \%$ were comfortable with biosimilar extrapolation

3. $55.2 \%$ of respondents were unsure or concerned about biosimilar safety, particularly rheumatologists and dermatologists

4. Most physicians were interested in learning more about biosimilar concepts from trusted sources: journals, peer physicians, congresses/symposia

1. $25 \%$ felt highly confident about biosimilar safety/ efficacy when initiating treatment in biologic-naive patients

2. $71 \%$ would not switch patients in prolonged remission with an originator $\mathrm{mAb}$ to a biosimilar $\mathrm{mAb}$ (citing lack of disease-specific interchangeability evidence and immunogenicity concerns)

3. $24 \%$ were comfortable with biosimilar extrapolation to all originator approved indications

4. Most clinicians believed medical societies should provide biosimilar information, develop multispecialty practice guidelines, and develop rules on biosimilar use

1. $60 \%$ of physicians expressed a high confidence level in biosimilar safety and efficacy when initiating treatment in biologic-naive patients

2. $40 \%$ of gastroenterologists would not switch a stable patient in prolonged remission with an originator $\mathrm{mAb}$ to a biosimilar $\mathrm{mAb}$

3. $51 \%$ were comfortable with biosimilar extrapolation to all originator approved indications

4. $56 \%$ judged that biosimilar educational activities were fair and adequate, while $15 \%$ found the education confusing and $13 \%$ found it too optimistic about safety and efficacy

\section{Sample size: $\mathrm{n}=131$}

Response rate: $13.67 \%$

Sampling: N/A

Methods: online survey

Sample: rheumatologists

Date: 12/09/16-12/14/16
To evaluate U.S

rheumatologists familiarity with biosimilars and biosimilarity the concept of barriers in Belgium

1. Lack of confidence in biosimilars was attributed to lack of clinical data supporting safe and effective use of biosimilars

2. Most interviewees believed biosimilar prescribing should be restricted to biologic-naive patients

3. Originator manufacturing discounts exceed the price difference of biosimilars, thwarting initiatives to prescribe

\section{1. $99 \%$ had prescribed an anti-TNF alpha mAb}

2. $74 \%$ were either extremely or moderately familiar with the FDA's biosimilar definition

3. $66 \%$ were extremely likely or likely to initiate biosimilar therapy in biologic treatment-naive RA patients

4. Only 34\% were extremely likely or likely to initiate biosimilar therapy for biologic treatment-naive patients in an extrapolated indication

5. $60 \%$ were unlikely to switch from the bio-originator to a biosimilar in TNF alpha mAb patients doing well, regardless of rheumatologic indication

\section{Sample size: $\mathrm{n}=210$}

Response rate: $22.8 \%$

Sampling: N/A

Methods: online survey

Sample: specialty physicians

Date: 04/2015 the content of the European biosimilar label
1. $59 \%$ had already prescribed a biosimilar

2. Physicians refer to peer-reviewed journals, professional guidelines, and prescription labels (>90\% for all 3) for biological product information

3. The majority of respondents expressed a need to learn more about the origin of the clinical data and the distinction of adverse events by class and individual product
Main Limitations

Only 1 biosimilar was approved and marketed in the United States at the time of the survey

Not reported

Could not guarantee the same respondents between 2013 and 2015 surveys

Interviews conducted from 10/2012 to of originators and biosimilars could have since evolved

\section{Conference poster} (not peer-reviewed publication)

\section{Not reported} 02/2013. Perception preferences for 


\section{TABLE 1 Summary of Key Information from Articles that Met Inclusion Criteria (continued)}

Author, Country,

Journal

Kellner et al. 33

Europe

Ann Rheum Dis

2016

\begin{tabular}{l|l} 
Study Description & Objective
\end{tabular}

Sample size: $\mathrm{n}=222$

Response rate: N/A

Sampling: N/A

Methods: online survey

Sample: rheumatologists

Date: 06/2016-08/2015

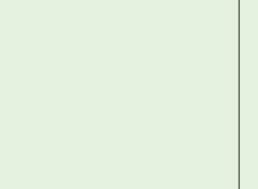

Narayanan et al. ${ }^{34}$

United Kingdom,

France, Italy, Spain,

Germany

Clin Exp Rheumatol

2016
Sample size: $\mathrm{n}=100$

Response rate: $35 \%$

Sampling: N/A

Methods: online survey

Sample: rheumatologists

Date: 04/2013-05/2013
Sample size: $\mathrm{n}=143$

pharmacists, $n=377$

physicians

Response rate: $72 \%$

pharmacists, $9 \%$ physicians

Sampling: N/A

Methods: online survey

Target group: physicians,

community pharmacists

Date: 04/2016-05/2016

Pand

Pasina et al. ${ }^{25}$

Italy

Eur J Med

2016
Sample size: $\mathrm{n}=579(\mathrm{n}=214$ specialists for survey; $\mathrm{n}=36$

hospital pharmacists)

Response rate: N/A

Sampling: N/A

Methods: online survey

Sample: specialty physicians,

hospital pharmacists

Date: 04/01/15-09/30/15
Sample size: $\mathrm{n}=36$

Response rate: N/A

Sampling: N/A

Methods: online survey

Sample: physicians

Date: not reported
To evaluate awareness and attitudes to biosimilars among medical specialists, general practitioners, and community pharmacists
To assess perspectives, knowledge, and prescribing comfort of biosimilar medicines
To assess the factors underlying rheumatologists perceptions of biosimilars for managing RA
1. $97 \%$ of rheumatologists indicated being familiar or very familiar with biosimilars, yet only $48 \%$ identified the correct EMA biosimilar definition

2. $65 \%$ cited limited or no knowledge of biologic development processes

3. Average comfort level in prescribing biosimilars was 6.5 on a scale of 1 to 10 (with 10 being extremely comfortable)

4. Most rheumatologists preferred to prescribe biosimilars in biologic treatment-naive patients or those who stopped responding to current biologic therapy

1. $60 \%$ doubted similarity to the reference product, and Small sample size $53 \%$ questioned biosimilar safety and efficacy data

2. Despite this, $60 \%$ reported that they would definitely or be highly likely to prescribe a biosimilar in an eligible RA patient

3. $60 \%$ would try using biosimilars for $1-2$ years among a small group of patients before expanding practice use

4. Years of practice experience had no effect on physician perceptions and willingness to prescribe biosimilars, although more physicians with $>20$ years of experience identified lack of long-term data as a key issue impeding biosimilar prescribing

\section{Pharmacists (75.2\%) and medical specialists (85.3\%)} were more familiar with biosimilars than general practitioners (40.3\%)

2. $21 \%$ of clinicians mistook a biosimilar as the same as a generic medicine

3. $67 \%$ would prescribe a biosimilar in treatment-naive patients; only $28 \%$ would switch from an originator medicine to a biosimilar when a patient is clinically stable

4. Pharmacists referred to medical information from the manufacturer (44\%) more so than medical specialists (17\%) and general practitioners (7\%) to learn details about biologic/biosimilar medicines

To assess hospital specialists' attitudes toward prescribing biosimilars and to collect hospital specialists' opinions about the quality, safety, and efficacy of biosimilars only available

\author{
ly
}

.

\section{1.} of survey respondents expressed complete or good knowledge about scientific principles of biosimilars

2. $51 \%$ prescribed biosimilars only to biologic-naive patients. Only 25\% would prescribe biosimilars to treatment-naive patients and/or patients with previous bio-originator exposure

3. More clinicians expressed doubts about the scientific validity and lack of clinical trial data for biosimilar indication extrapolation than pharmacists (41\% vs. $8 \%)$

4. Pediatricians and nephrologists cited more favorable experiences with/opinions of biosimilars than gastroenterologists and rheumatologists

1. $22 \%$ of physicians were regular biosimilar prescribers ( $\geq 1$ prescription/week), 30.5\% were occasional prescribers (between 6 and 12 prescriptions/year), and $47 \%$ were potential prescribers $(<6$ prescriptions/year)

2. $53 \%$ emphasized the lack of high-level safety evidence for biosimilars

3. Physicians expressed concerns about biosimilar efficacy, especially in extrapolated indications
Main Limitations

Conference abstract

Eur J Hosp Pharm

Sci Pract

2016

about biosimilars

French hospital

\section{Selection bias;} response rates varied between pharmacists, medical specialists, and general practitioners; hospital pharmacists were not represented in the study

Conference abstract only available 
TABLE 1 Summary of Key Information from Articles that Met Inclusion Criteria (continued)

\begin{tabular}{|c|c|c|c|c|}
\hline $\begin{array}{l}\text { Author, Country, } \\
\text { Journal }\end{array}$ & Study Description & Objective & Outcomes & Main Limitations \\
\hline $\begin{array}{l}\text { Sullivan et al. }{ }^{23} \\
\text { Germany } \\
\text { PLoS ONE } \\
2017\end{array}$ & $\begin{array}{l}\text { Sample size: } \mathrm{n}=25 \\
\text { Response rate: N/A } \\
\text { Sampling: N/A } \\
\text { Methods: online survey } \\
\text { Sample: gastroenterologists } \\
\text { Date: } 12 / 2015-03 / 2016\end{array}$ & $\begin{array}{l}\text { To evaluate } \\
\text { gastroenterologists' } \\
\text { willingness } \\
\text { to prescribe } \\
\text { biosimilars and } \\
\text { explore patient } \\
\text { attitudes to } \\
\text { biosimilars }\end{array}$ & $\begin{array}{l}\text { 1. Biosimilars constitute } 12 \%-13 \% \text { of biologic drugs } \\
\text { physicians prescribe } \\
\text { 2. Notwithstanding prescribing quotas, } 88 \% \text { of } \\
\text { gastroenterologists would prescribe a bio-originator } \\
\text { to a biosimilar as first-line therapy; the bio-originator } \\
\text { was still preferred for third-line therapy in UC }(92 \%) \\
\text { and CD }(76 \%) \\
\text { 3. Most physicians would use biosimilars when a } \\
\text { treatment change is required }\end{array}$ & $\begin{array}{l}\text { Only } 2 \text { infliximab } \\
\text { biosimilar compounds } \\
\text { were approved at time } \\
\text { of survey; sample size } \\
\text { was not representative } \\
\text { of all practicing } \\
\text { gastroenterologists }\end{array}$ \\
\hline $\begin{array}{l}\text { van Overbeeke } \\
\text { et al. }{ }^{19} \\
\text { Belgium } \\
\text { BioDrugs } \\
2016\end{array}$ & $\begin{array}{l}\text { Sample size: } \mathrm{n}=41 \\
\text { Response rate: N/A } \\
\text { Sampling: N/A } \\
\text { Methods: online survey } \\
\text { Sample: rheumatologists } \\
\text { Date: 01/2016-03/2016 }\end{array}$ & $\begin{array}{l}\text { To measure } \\
\text { the current } \\
\text { comparative } \\
\text { knowledge and } \\
\text { perception of } \\
\text { rheumatologists } \\
\text { and Belgian RA } \\
\text { patients regarding } \\
\text { bio-originators and } \\
\text { biosimilars }\end{array}$ & $\begin{array}{l}\text { 1. Sources of biosimilar physician education included } \\
\text { manufacturers, government bodies, and congress } \\
\text { 2. Only } 7 \% \text { of rheumatologists had prescribed a } \\
\text { biosimilar; } 60 \% \text { would prescribe a biosimilar in } \\
\text { biologic-naive patients only } \\
\text { 3. Physicians questioned the quality, safety, and } \\
\text { interchangeability of biosimilars more so than RA } \\
\text { patients } \\
\text { 4. Reasons for not prescribing a biosimilar included } \\
\text { "less studied than the originator" and "no clinical } \\
\text { trials conducted in the specific indication" }\end{array}$ & $\begin{array}{l}\text { Small physician } \\
\text { response rate; online } \\
\text { survey response } \\
\text { options were limited }\end{array}$ \\
\hline $\begin{array}{l}\text { Waller et al. }{ }^{24} \\
\text { Germany } \\
\text { Patient Prefer } \\
\text { Adherence } \\
2017\end{array}$ & $\begin{array}{l}\text { Sample size: } 50 \\
\text { Response rate: } 18 \% \\
\text { Sampling: N/A } \\
\text { Methods: online survey } \\
\text { Sample: rheumatologists } \\
\text { Date: } 12 / 2015-03 / 2016\end{array}$ & $\begin{array}{l}\text { To evaluate if } \\
\text { rheumatologist } \\
\text { biologic prefer- } \\
\text { ences match } \\
\text { actual prescribing } \\
\text { behavior and } \\
\text { explore patient } \\
\text { attitudes to } \\
\text { biosimilars }\end{array}$ & $\begin{array}{l}\text { 1. Biosimilars constitute }<10 \% \text { of biologic drugs } \\
\text { physicians prescribe } \\
\text { 2. Notwithstanding prescribing quotas, } 95 \% \text { would } \\
\text { prescribe a bio-originator to a biosimilar as either } \\
\text { first- or second-line therapy; the bio-originator was } \\
\text { still preferred for third-line therapy by } 80 \%-92 \% \text { of } \\
\text { physicians } \\
\text { 3. Most physicians would use biosimilars when a } \\
\text { treatment change is required }\end{array}$ & Small sample size \\
\hline
\end{tabular}

$C D=$ Crohn's disease; $E C C O=$ European Crohn's and Colitis Organisation; FDA =U.S. Food and Drug Administration; mAb= monoclonal antibody; N/A=not applicable; NICE = National Institute for Health and Care Excellence; RA = rheumatoid arthritis; TNF=tumor necrosis factor; UC=ulcerative colitis.

\section{Gaps in Biosimilar Knowledge}

There was a lack of biosimilar awareness in Europe and the United States. In Pasina et al. (2016), only $22.9 \%$ of physicians and $38.8 \%$ of pharmacists indicated having complete or good knowledge about biosimilars. ${ }^{25}$ Likewise, in Cassar et al. (2016), only 6\% of physicians were familiar with biosimilarity, 35\% had a basic understanding, and 59\% could not define biosimilars or had never heard of them. ${ }^{27}$ Approximately 55\% of rheumatologists in Beck et al. (2016) had little knowledge of biosimilars; lack of knowledge was greater among office-based physicians (23.7\%) than hospital-based physicians (61.8\%). ${ }^{21}$

Higher familiarity with biosimilars was reported by $97 \%$ of rheumatologists in Kellner et al. (2016), but only 48\% correctly identified the EMA definition of a biosimilar. ${ }^{33}$ In Sidikou et al. (2016), 61\% of physicians reported good biosimilar knowledge and $70 \%$ reported a high level of confidence for biosimilar use. $^{22}$ Only half of respondents had actually prescribed biosimilars at the time of the survey. ${ }^{22}$ In Barsell et al. (2017), 62\% of dermatologists had a basic understanding of biosimilars, $27 \%$ reported a complete understanding, and $11 \%$ reported that they have never heard of biosimilars. ${ }^{15}$ Of those who reported having a complete understanding of biosimilars, 21\% incorrectly described a biosimilar as a generic copy of a biologic molecule. ${ }^{15}$ Similarly, $21 \%$ of participants in O'Callaghan et al. (2017) mistook biosimilars as generic biologic medicines. More pharmacists reported having a higher biosimilar familiarity than general practitioners $(75.2 \%$ vs. $40.3 \%$; $P<0.01){ }^{26}$ Van Overbeeke et al. (2017) reported the highest level of biosimilar knowledge among respondents at 90\%. Per the study, participating rheumatologists had already received information on the launch of biosimilars and the patent expirations from "different, well-balanced sources."19

In Cohen et al. (2016), 55\% of rheumatologists and 32.8\% of gastroenterologists were unaware that biosimilar filgrastim was marketed and available for use. ${ }^{16}$ More recently, in Gibofsky et al. (2017), 84\% of rheumatologists knew about biosimilar infliximab's approval, but only $47 \%$ and 34\% knew about the respective biosimilar adalimumab and biosimilar etanercept approvals. ${ }^{17}$ In Chapman et al. (2017), 75\% of clinicians were aware that biosimilars were available on their local formulary.

\section{Clinical Concerns}

Clinicians were hesitant about biosimilar safety, efficacy, extrapolation, and pharmacy-driven substitution. Most safety 
concerns regarded immunogenicity, or the propensity of the biosimilar to generate an immune response to itself and other related proteins. ${ }^{35}$ In Pasina et al. (2016), 23\% of respondents believed biosimilars had a higher immunogenicity risk than bio-originators, with poor-quality approval trials. ${ }^{25}$ Greater than $60 \%$ of physicians in Barsell et al. (2017), Cohen et al. (2016), Beck et al. (2016), O'Callaghan et al. (2017), and Danese et al. (2014) were also concerned about biosimilar immunogenicity. 15,16,21,26,30 Immunogenicity concerns decreased from 67\% to $27.1 \%$ in Danese et al. (2016) over a 2-year period. ${ }^{31}$

Providers doubted biosimilar safety and efficacy in extrapolated indications. Indication extrapolation refers to the approval of a biosimilar for indications held by the bio-originator but that were not directly evaluated during the biosimilar's clinical trials. Approximately 39\% of rheumatologists in van Overbeeke et al. (2017) and 64\% of pharmacists in Adé et al. (2017) opposed indication extrapolation. ${ }^{19,20}$ In Danese et al. (2016), 32.2\% of gastroenterologists opposed extrapolation across other specialty (e.g., rheumatic) indications, and 25\% opposed extrapolation across IBD. ${ }^{31}$ In Baji et al. (2016), 65\% of clinicians had concerns about biosimilar use in Crohn's disease (efficacy, $\mathrm{n}=2$; safety, $\mathrm{n}=7$; efficacy and safety, $\mathrm{n}=21$ ), and $12 \%$ opposed biosimilar use altogether due to the lack of evidence from randomized controlled trials in this indication. Physicians in Beck et al. (2016) cited the most common barriers to biosimilar use as extrapolation of efficacy and safety to all indications of the bio-originator (67.2\%) and the lack of longterm tolerability data $(66.1 \%){ }^{21}$

Interchangeability and pharmacy-led switching also incited provider concerns. An interchangeable biosimilar, by definition, is expected to produce the same clinical result as the reference product in any given patient; some U.S. state laws allow an interchangeable biosimilar to be substituted for the reference product at the pharmacy level, without notifying the patient's physician. In Danese et al. (2016), only 44\% of respondents considered biosimilars interchangeable (improved from 6\% noted in Danese et al.), while 39.9\% did not due to insufficient data supporting interchangeability. ${ }^{30,31}$ Furthermore, 89.8\% disagreed with pharmacy-driven automatic substitution of the bio-originator with a biosimilar. ${ }^{31}$ Similar beliefs were noted in Barsell et al. (2017), Cassar et al. (2016), and O'Callaghan et al. (2017). ${ }^{15,26,27}$ In O'Callaghan et al., 61\% of physicians and $58 \%$ of pharmacists believed switching should solely be the prescriber's decision. ${ }^{26}$ In Adé et al. (2017), 95\% of pharmacists believed interchanging biosimilars for bio-originators was a joint physician-pharmacist responsibility. ${ }^{20}$

In Cohen et al. (2016), 80\% of respondents were unaware that interchangeability could enable pharmacist-led switching. ${ }^{16}$ A later U.S. survey conducted by Gibofsky et al. (2017) found that $71 \%$ of rheumatologists were knowledgeable about interchangeability, and $74 \%$ indicated an interchangeable designation would be very or moderately important. ${ }^{17}$ Positive attitudes about interchangeability were also noted in Chapman et al. (2017), in which $>90 \%$ of physicians had no or minor safety or efficacy concerns when switching patients. ${ }^{29}$

\section{Biosimilar Education Programs for Providers}

Self-study and peer-reviewed journals/professional guidelines were the 2 primarily trusted sources of biosimilar information in both the U.S. and Europe. 16,18,21,26,32 Discussion with physician and pharmacist colleagues was also a reliable means of biosimilar information. ${ }^{16,21}$ Additional sources of biosimilar education included manufacturer promotional materials, continuing education programs, and conference/seminar attendance. ${ }^{19,21,26}$ O'Callaghan et al. (2017) uniquely found that pharmacists (44\%) were more likely than medical specialists (13\%) and general practitioners (7\%) to consult manufacturer promotional materials to learn more about the biosimilar product. ${ }^{26}$ Danese et al. (2016) was the only survey to grade biosimilar educational activities. ${ }^{31}$ Overall, gastroenterologists found biosimilar educational activities favorable (56\%), unnecessary (16\%), too confusing (15\%), or too optimistic about safety and efficacy (13\%). ${ }^{31}$ The exact educational activities were not defined. ${ }^{31}$

\section{Discussion}

To our knowledge, this is the first systematic review designed to assess health care practitioner understanding, perceptions, and prescribing culture of biosimilar medicines through 2017. Most reviewed studies were set outside of the United States (85\%) and primarily surveyed gastroenterologists, rheumatologists, and specialty physicians who routinely prescribed bio-originators in clinical practice. While this review also included pharmacists, only 4 studies evaluated pharmacist perspectives. ${ }^{18,20,26,29}$

Overall, biosimilar prescribing rates varied between countries and among practitioner types. In a 2015 French survey, for example, $7 \%$ of rheumatologists prescribed biosimilars. ${ }^{21}$ In a second French study (survey year not available), nearly 99\% of physicians wrote more than 1 biosimilar prescription per year. ${ }^{22}$ In nearby Germany, biosimilars made up approximately $13 \%$ of the biologic therapies gastroenterologists prescribed and approximately 10\% of biologic therapies rheumatologists prescribed, demonstrating limited biosimilar uptake. ${ }^{23,24}$ In comparison, $72 \%$ of rheumatologists in Kellner et al. (2016) reported prescribing biosimilar infliximab to at least 1 patient..$^{33}$ A positive trend toward increasing length of biosimilar exposure and willingness to prescribe biosimilars was reported by 2 studies, suggesting that time and experience favorably affect biosimilar prescribing behavior. ${ }^{31,33}$

This review also identified gaps in biosimilar knowledge and understanding among clinicians. The majority of surveyed physicians indicated having an incomplete or basic awareness of biosimilar medicines, with familiarity higher 
among hospital-based than office-based practitioners. ${ }^{16,21,25-27}$ Pharmacists, on average, indicated having a higher level of biosimilar familiarity than physicians. ${ }^{18,25,26}$ Of physicians who reported having a high familiarity with biosimilars in Kellner et al. (2016) and Barsell et al. (2017), approximately 48\% and $21 \%$, respectively, incorrectly defined biosimilarity, highlighting a discrepancy between claimed biosimilar knowledge and actual awareness. ${ }^{15,33}$ In Cohen et al. (2016) and Gibofsky et al. (2017), greater than 50\% of U.S. physicians were unaware of the most recent U.S. biosimilar approvals ${ }^{16,17}$; this lack of awareness likely contributes to decreased biosimilar prescribing and uptake in the United States.

Notably, both U.S. and European clinicians seemed to be unaware of the existence of biosimilars as alternative safe and effective treatment options for their patients. Most physicians perceived biosimilar medicines as second- or third-line treatment options in patients requiring biologic therapy and restricted use to biologic treatment-naive patients only. 17,23-26,28,29 Underlying safety (particularly immunogenicity) and efficacy concerns deterred most physicians from switching patients already tolerating sustained bio-originator therapy to the biosimilar agent. ${ }^{14,15,16,20,24-29,30}$ Furthermore, the lack of longterm tolerability data and lack of biosimilar data altogether in extrapolated indications evoked considerable concern, curtailing biosimilar prescribing and uptake. ${ }^{19-21,28,31}$

Means of health care provider biosimilar education were vaguely described. Self-instruction and independent guideline and/or journal article review were the most common learning methods, followed by colleague discussion, continuing education, and consulting promotional manufacturer materials. ${ }^{16,18,19,21,26,32}$ Importantly, physicians who received information on the launch of biosimilars and biologic patent expirations in van Overbeeke et al. (2017) reported the highest level of biosimilar knowledge among all survey respondents at $90 \% .{ }^{19}$ Although the exact means of biosimilar education were not reported, van Overbeeke et al. suggested a positive relationship between biosimilar education and biosimilar knowledge. ${ }^{19}$ Irrespective of the method, our review indicates a strong need for clinician-directed biosimilar education to strengthen biosimilar familiarity, augment understanding, and promote acceptance of biosimilar medications as safe and effective treatment options for patients.

Biosimilar education should address the key areas of provider concern identified in this review: immunogenicity, clinical trial evidence, extrapolation, and interchangeability. Since the reviewed surveys were conducted, newer data have emerged supporting biosimilar switching. ${ }^{36,37}$ Education detailing the key findings and implications of these recently published studies will likely facilitate understanding and inform policies that govern biosimilar use. Per an AMCP Partnership Forum, biosimilar education should also address biosimilar pharmacokinetics and pharmacodynamics and medical billing/electronic health record documentation processes. ${ }^{38}$ The AMCP Forum further recommends developing novel educational tools (e.g., online webinars) to supplement traditional educational methods (e.g., policy statements, white papers, e-dossiers). ${ }^{38}$

Only 2 publications have directly explored the effects of biosimilar education on clinician attitudes and/or prescribing habits. Per results presented by Murphy et al. (2017) at a conference, Cancer Vanguard implemented 12 biosimilar training sessions to oncology staff from January to April 2017. Before training, $86 \%$ of nurses and $43 \%$ of doctors had not heard of the term "biosimilar/biosimilarity" in the preceding month, and $40.1 \%$ of participants were unsure if biosimilars would yield the same efficacy response as originator biologics. ${ }^{39}$ After training, participants' confidence in using biosimilars grew from mean (standard deviation) scores of 3.1 (3.2) to 7.1 (2.1; $P<0.001$ ), and $95 \%$ believed biosimilars had the same efficacy as bio-originators. ${ }^{39}$ Thus, Murphy et al. presented preliminary results demonstrating a structured biosimilar educational program's ability to improve provider biosimilar confidence. ${ }^{39}$

Trotta et al. (2017) compared prescribing patterns of granulocyte colony-stimulating factor (G-CSF) biosimilars pre- and post-implementation of a biosimilar working group formed in May 2015 to promote the rational and appropriate use of biosimilars. ${ }^{40}$ The group developed evidence-based guidelines and recommended cost-effective approaches for biosimilar G-CSF procurement and prescribing. A pre-/post-analysis showed that filgrastim biosimilar use increased from $34.4 \%$ to $49.8 \%$ 7 months after the intervention's implementation $(P<0.0001){ }^{40}$ This study was the first to demonstrate that sharing biosimilar information with clinicians yielded significant changes in prescribing behavior. Biosimilar education, therefore, not only improves provider understanding and confidence but also elicits actual prescribing changes and increases biosimilar use.

\section{Limitations}

This study has several limitations. First, only 1 individual screened full-text articles for inclusion and extracted data. A second individual then reviewed the extracted data for accuracy and completeness but did not separately extract data from each study. This process potentially introduced bias in how results were reported. Second, most of the included articles had design limitations, including unreported response rates, small and highly varied sample sizes, and nonvalidated questionnaires. Sampling methods were rarely reported; thus, samples may not have been representative of the entire population. Third, the reviewed surveys were conducted at varying time points and in different countries with differing laws and policies. No statistical methods were used in this review to correlate survey results. Instead, overall trends in the literature were noted. As biosimilar market uptake is a time-sensitive matter, health care provider perceptions of biosimilars may have since evolved and will likely continue to evolve over time. 


\section{Conclusions}

Findings from this study indicate that clinicians in the United States and Europe are cautious about biosimilar use and do not predominantly support the use of biosimilars as safe and effective treatment options in patients already receiving bio-originator therapy. Provider hesitancies deter biosimilar prescribing and use. Biosimilar education can help to increase prescriber comfort and familiarity with biosimilar medicines, inspire prescribing changes, and ultimately drive biosimilar use. However, biosimilar-specific education remains a relatively neglected area of emphasis in the published literature. This review identifies several topics that clinician-tailored biosimilar education should address to alleviate existing misunderstandings and bridge knowledge gaps altogether. Major areas of focus include thoroughly reviewing the concepts of immunogenicity, extrapolation, and interchangeability. Future research should explore different health care provider types in greater detail and evaluate practitioners' engagements with patients to ensure that providers can effectively communicate with their patients about biosimilars as a treatment option. A mixed-methods study including exploratory semistructured qualitative interviews and a quantitative survey assessment of U.S. and/or European clinicians should be conducted to assess perceived biosimilar educational needs.

\section{Authors}

EMILY LEONARD, PharmD Candidate, and DELESHA CARPENTER, PhD, MSPH, Division of Pharmaceutical Outcomes and Policy, UNC Eshelman School of Pharmacy, University of North Carolina at Chapel Hill. MICHAEL WASCOVICH, PharmD, MBA, Pharmacy Services; SONIA OSKOUEI, PharmD, Pharmacy Program Development (Biosimilars); and PAULA GURZ, MBA, Pharmacy Contracting, Generics, Biosimilars, Premier, Charlotte, North Carolina.

AUTHOR CORRESPONDENCE: Emily Leonard, PharmD Candidate, UNC Eshelman School of Pharmacy, University of North Carolina at Chapel Hill, 301 Pharmacy Ln., Chapel Hill, NC 27599. Tel.: 203.417.3241; E-mail: Emily_Leonard@unc.edu.

\section{DISCLOSURES}

No outside funding supported this study. The authors have nothing to disclose.

\section{REFERENCES}

1. Schumock GT, Li EC, Wiest MD, et al. National trends in prescription drug expenditures and projections for 2017. Am J Health Syst Pharm. 2017;74(15):1158-73.

2. Mócsai A, Kovács L, Gergely P. What is the future of targeted therapy in rheumatology: biologics or small molecules? BMC Med. 2014;12(1):1-9.
3. U.S. Food and Drug Administration. Biosimilar development, review, and approval. 2017. Available at: https://www.fda.gov/Drugs/ DevelopmentApprovalProcess/HowDrugsareDevelopedandApproved/ ApprovalApplications/TherapeuticBiologicApplications/Biosimilars/ ucm580429.htm. Accessed November 1, 2018.

4. Generics and Biosimilars Initiative. Biosimilars approved in the U.S. February 9, 2018. Available at: www.gabionline.net/Biosimilars/General/ Biosimilars-approved-in-the-US. Accessed November 1, 2018.

5. Generics and Biosimilars Initiative. Biosimilars approved in Europe. February 2, 2018. Available at: http://www.gabionline.net/Biosimilars/ General/Biosimilars-approved-in-Europe. Accessed

November 1, 2018.

6. Frost \& Sullivan. Biosimilars market, Europe, forecast to 2025. March 29, 2017. Available at: http://www.frost.com/c/10300/sublib/frost-content.do?sheetName=report-overview\&sheetGroup=MCAA-01-00-0000\&viewName=virtual-brochure $\&$ repid=MCAA-01-00-00-00. Accessed November 1, 2018.

7. Moorkens E, Jonker-Exler C, Huys I, Declerck P, Simoens S, Vulto AG. Overcoming barriers to the market access of biosimilars in the European Union: the case of biosimilar monoclonal antibodies. Front Pharmacol. 2016;7:1-9.

8. QuintilesIMS. Delivering on the potential of biosimilar medicines: the role of functioning competitive markets introduction. March 2016. Available at: https:// www.medicinesforeurope.com/wp-content/uploads/2016/03/IMS-InstituteBiosimilar-Report-March-2016-FINAL.pdf. Accessed November 1, 2018.

9. Bocquet F, Degrassat-Theas A, Cordonnier A, et al. Biosimilar infliximab: feedback after a one-year use in 37 Paris public hospitals [abstract]. Value Health. 2017;20(5):A19.

10. Sarpatwari A, Gagne JJ, Levidow NL, Kesselheim AS. Active surveillance of follow-on biologics: a prescription for uptake. Drug Saf. 2017;40(2):105-08

11. Rémuzat C, Dorey J, Cristeau O, Ionescu D, Radière G, Toumi M. Key drivers for market penetration of biosimilars in Europe. J Mark Access Heal Policy. 2017;5(1):1272308.

12. Aapro MS. What do prescribers think of biosimilars? Target Oncol. 2012;7:51-55.

13. Biosimilars/Biobetters Pipeline Directory. Biotechnology Information Institute. 2018. Available at: http://www.biosimilarspipeline.com/. Accessed November 1, 2018.

14. van den Hoven A. Biosimilar medicines: practical EU experience and perspectives. Paper presented at: 2017 AAM Biosimilars Council Conference; September 12, 2017; Washington, DC.

15. Barsell A, Rengifo-Pardo M, Erlich A. A survey assessment of U.S. dermatologists' perceptions of biosimilars. J Drugs Dermatol. 2017;16(6):612-15.

16. Cohen H, Beydoun D, Chien D, et al. Awareness, knowledge, and perceptions of biosimilars among specialty physicians. Adv Ther. 2016;33(12):2160-72.

17. Gibofsky A, Badawi S. Biosimilar knowledge among U.S. rheumatologists—a survey [abstract]. Arthritis Rheumatol. 2017;69(Suppl 10). Available at: https://acrabstracts.org/abstract/biosimilar-knowledge-among-us-rheumatologists-a-survey/. Accessed November 7, 2018.

18. Dylst P, Vulto A, Simoens S. Barriers to the uptake of biosimilars and possible solutions: a Belgian case study. Pharmacoeconomics. 2014;32(7):681-91.

19. van Overbeeke E, De Beleyr B, de Hoon J, Westhovens R, Huys I. Perception of originator biologics and biosimilars: a survey among Belgian rheumatoid arthritis patients and rheumatologists. BioDrugs. 2017;31(5):447-59.

20. Adé A, Bourdon O, Bussières JF. A survey of pharmacists' knowledge and views of biosimilars in Quebec and France. Ann Pharm Fr. 2017;75(4):267-75.

21. Beck M, Michel B, Rybarczyk-Vigouret MC, et al. Rheumatologists' perceptions of biosimilar medicines prescription: findings from a French webbased survey. BioDrugs. 2016;30(6):585-92. 
22. Sidikou O, Mondoloni P, Leroy B, Renzullo C, Coutet J, Penad JF. Biosimilars: what do clinicians actually think [abstract]? Eur J Hosp Pharm Sci Pract. 2016;23(Suppl 1):A47. Available at: https://ejhp.bmj.com/content/23/Suppl_1/A47.2. Accessed November 7, 2018.

23. Sullivan E, Piercy J, Waller J, Black CM, Kachroo S. Assessing gastroenterologist and patient acceptance of biosimilars in ulcerative colitis and Crohn's disease across Germany. PLoS One. 2017;12(4):e0175826.

24. Waller J, Sullivan E, Piercy J, Black CM, Kachroo S. Assessing physician and patient acceptance of infliximab biosimilars in rheumatoid arthritis, ankylosing spondylarthrosis and psoriatic arthritis across Germany. Patient Prefer Adherence. 2017;11:519-30.

25. Pasina L, Casadei G, Nobili A. A survey among hospital specialists and pharmacists about biosimilars. Eur J Intern Med. 2016;35:e31-33.

26. O'Callaghan J, Bermingham M, Leonard M, et al. Assessing awareness and attitudes of health care professionals on the use of biosimilar medicines: a survey of physicians and pharmacists in Ireland. Regul Toxicol Pharmacol. 2017;88:252-61.

27. Cassar K, Zammit Dimech D, Grech L, Balzan D, Cutajar A, Cassar PJ. Biosimilars: the perception amongst Maltese clinicians [abstract]. Ann Rheum Dis. 2016;75(Suppl 2):1294. Available at: https://ard.bmj.com/content/75/ Suppl_2/1294.1. Accessed November 7, 2018.

28. Baji P, Gulacsi L, Lovasz B, et al. Treatment preferences of originator versus biosimilar drugs in Crohns disease; discrete choice experiment among gastroenterologists. Scand J Gastroenterol. 2016;51(1):22-27.

29. Chapman SR, Fitzpatrick RW, Aladul MI. Knowledge, attitude and practice of health care professionals towards infliximab and insulin glargine biosimilars: result of a UK web-based survey. BMJ Open. 2017;7(6):e016730.

30. Danese S, Fiorino G, Michetti P. Knowledge and viewpoints on biosimilar monoclonal antibodies among members of the European Crohn's and Colitis Organization. J Crohn's Colitis. 2014;8(11):1548-50.

31. Danese S, Fiorino G, Michetti P. Changes in biosimilar knowledge among European Crohn's Colitis Organization [ECCO] members: an updated survey. J Crohn's Colitis. 2016;10(11):1362-65.
32. Hallersten A, Fürst W, Mezzasalma R. Physicians prefer greater detail in the biosimilar label (SmPC)-results of a survey across seven European countries. Regul Toxicol Pharmacol. 2016;77:275-81.

33. Kellner H, Domènech E, Lakatos PL, et al. Awareness and acceptance of biosimilars by rheumatologists in eleven EU countries [abstract]. Ann Rheum Dis. 2016;75(Suppl 2):1008. Available at: https://www.researchgate.net/publication/310778558_AB0314_Awareness_and_Acceptance_of_Biosimilars_ by_Rheumatologists_in_Eleven_Eu_Countries. Accessed November 7, 2018.

34. Narayanan S, Nag S. Likelihood of use and perceptions towards biosimilars in rheumatoid arthritis: a global survey of rheumatologists. Clin Exp Rheumatol. 2016;34(1):9-11.

35. U.S. Food and Drug Administration. Guidance for industry: immunogenicity assessment for therapeutic protein products. August 2014. Available at: https://www.fda.gov/downloads/drugs/guidances/ucm338856.pdf. Accessed November 12, 2018.

36. Jørgensen KK, Olsen IC, Goll GL, et al. Switching from originator infliximab to biosimilar CT-P13 compared with maintained treatment with originator infliximab (NOR-SWITCH): a 52-week, randomised, double-blind, non-inferiority trial. Lancet. 2017;389(10086):2304-16

37. Davio K. 4 studies highlight biosimilar switching's effect on patients with IBD. The Center for Biosimilars. 2018. Available at: http://www.centerforbiosimilars.com/news/4-studies-highlight-biosimilar-switchings-effecton-patients-with-ibd. Accessed November 1, 2018.

38. AMCP Partnership Forum: biosimilars—ready, set, launch. J Manag Care Spec Pharm. 2016;22(4):434-40. Available at: https://dx.doi.org/10. 18553/jmcp.2016.22.4.434.

39. Murphy P, Amin V, Bill T, et al. Impact of education programme on biosimilar attitudes and beliefs. J Onc Pharm Pract. 2017;23(8):59-60.

40. Trotta F, Mayer F, Mecozzi A, Amato L, Addis A. Impact of guidance on the prescription patterns of G-CSFs for the prevention of febrile neutropenia following anticancer chemotherapy: a population-based utilization study in the Lazio region. BioDrugs. 2017;31(2):117-24. 